\title{
PROCESSING METHODS AND PREDICTIVE MODEL FOR WAVY-TILT-DAM MECHANICAL SEAL*
}

Yuechang Wang ${ }^{1}$ Ying Liu

Zhi $\mathrm{GaO}^{3}$

Weifeng Huang 4 Yuming Wang ${ }^{5}$

\begin{abstract}
A new method of manufacturing the wavy-tilt-dam(WTD) mechanical seal has been mentioned. In this method, the special equipment is designed to provide a predetermined force to external and inner circular surface of the ring. After milling the end face of the seal by grinding miller and releasing the preload, the wavy-tilt-dam can be done on the seal surface. In this paper, a prediction model is built up to investigate the relationship between the predetermined force and the deformation on the surface of the ring by using ANSYS software. A WTD ring is manufactured by this method which approves that the prediction model is in accord with the real process and this manufacturing method of the WTD mechanical seal is a proper choice.
\end{abstract}

Keywords: Mechanical seal; Wavy-tilt-dam; Manufacture; ANSYS; Predictive models.

1 Bachelor degree, Student, Department,of Mechnical Egineering, Tsinghua University, Beijing, China.

2 Dr. Degree, Associate Professor, Department, of Mechnical Egineering, Tsinghua University, Beijing, China.

3 Bachelor degree, Professor, Department, of Mechnical Egineering, Tsinghua University, Beijing, China.

4 Dr. Degree, Associate Professor, Department,of Mechnical Egineering, Tsinghua University, Beijing, China.

5 Bachelor degree, Professor, Department, of Mechnical Egineering, Tsinghua University, Beijing, China.

* Technical contribution to the $2^{\text {nd }}$ International Brazilian Conference on Tribology - TriboBR 2014, November $3^{\text {rd }}$ to $5^{\text {th }}$, 2014, Foz do Iguaçu, PR, Brazil. 


\section{INTRODUCTION}

The Wavy-Tilt-Dam(WTD) mechanical face seal, which has circumferential waves, a radial taper and seal dam, is widely used in high temperature, high pressure and high velocity industry area, especially in nuclear power plants. Iny [1] ,Lebeck [2], Young [3], Young, et al [4], Xu, et al [5] and Liu, et al [6-8] have done a lot of theoretical and experimental work on it. The results of their works confirm that WTD face seal not only have good steadystate working performance under extrem working condition, for example at higher temperature and high pressure, but also have better work stability under disturbance.

Due to the higher hardness of WTD face seal which is often made of WC, the manufacture of the micro-wave on the seal surface is very difficult. Young, et al [9] invent a method to produce the wavy on the seal surface. In this method, a predetermined force is applied to the peripheral surface of the seal ring by a special designed shrinking band which makes the end face of seal ring deformed. This kind of deformation is called the first pattern deformation. The band and seal ring is assembled by interference fit that the thermal assembling process is needed. Then the end face is processed with this pre-deformation by lapping machine. Finally, the pre-force is removed from the peripheral surface of the ring to allow the end face of the ring relaxing. The wavy deformation which is called the second pattern deformation is remained on the end face of the ring. Dai et al [10] offer another preload method which can produce the wavy face ring. They design the special equipment using the bolts to provide the pre-deformation on the inner and out peripheral surface of the seal ring respectively. Although Young et al and Dai et al give the principle of wavy face ring processing, the quantitative relationship between processing parameters and wave face geometry parameters is not mentioned. And the experimental research of the method also cannot be found.

In this paper, based on Dai's work, the detail theoretical analysis and producing experiment for WTD seal have been done. FEM (Finite Element Method) analysis model is developed to obtain the quantitative relationship between processing parameters and wave face geometry parameters. According to the FEM analysis results, the proper processing parameters are chosen to produce the full size WTD seal ring which is potential used for nuclear coolant pump. Some feasible solutions are developed for the difficulties encountered in the experiment.

\section{METHODS}

\subsection{Methods of Theoretical Analysis}

\subsubsection{Principle of the pressure pre-deformation method}

Figure 1 shows the principle of the pressure pre-deformation method for forming the WTD ring.

\footnotetext{
* Technical contribution to the $2^{\text {nd }}$ International Brazilian Conference on Tribology - TriboBR 2014, November $3^{\text {rd }}$ to $5^{\text {th }}$, 2014, Foz do Iguaçu, PR, Brazil.
} 


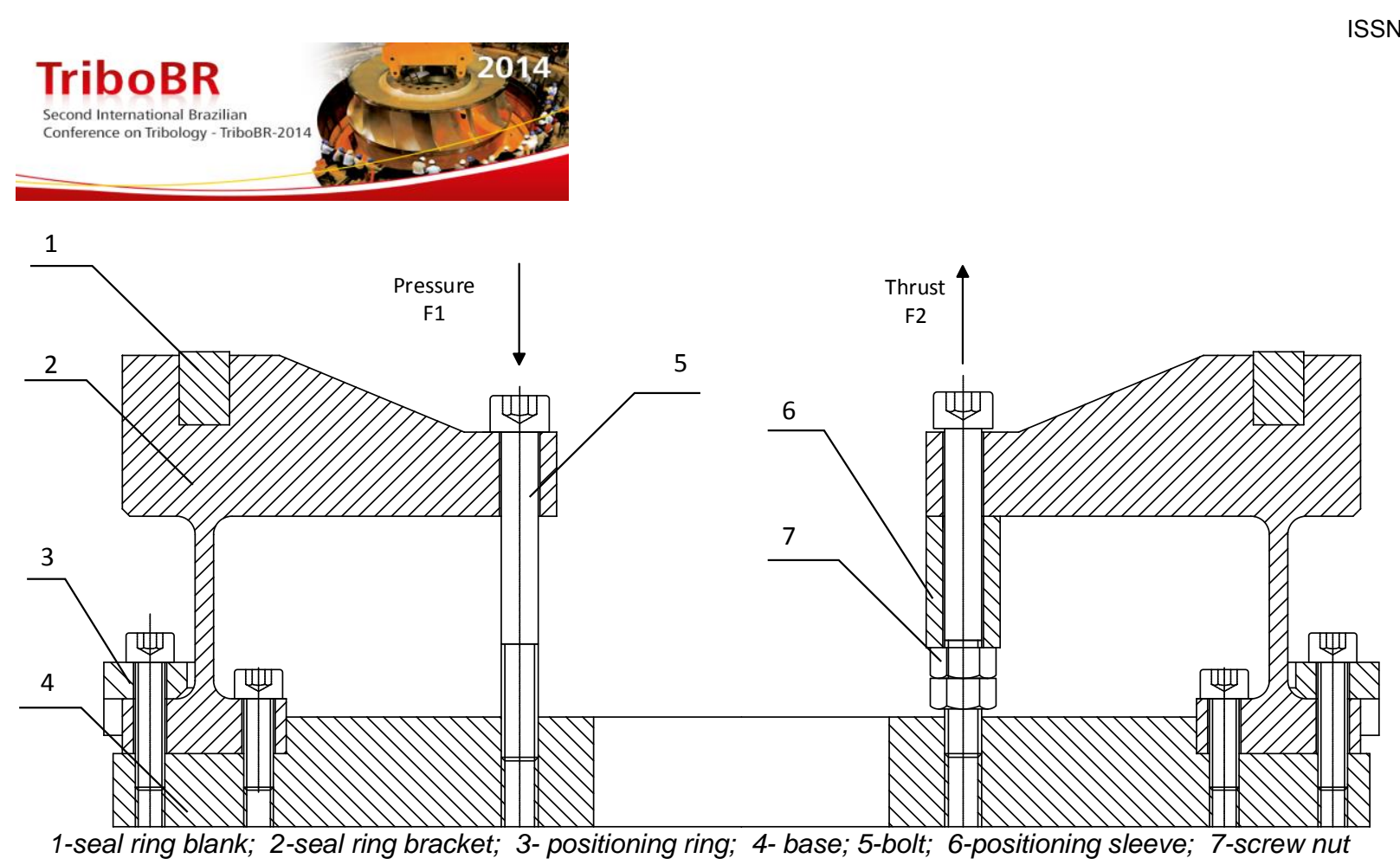

Figure 1. Schematic Diagram of the Principle of the pressure pre-deformation method.

The fixture of this method is combined with base, positioning ring, seal ring bracket, positioning sleeve and seal ring. There are totally 18 seal ring brackets, which are uniformly distributed circumferentially. The pre-loaded pressure is applied by the bolt 5. There are two kinds of load, $\boldsymbol{F}_{\mathbf{1}}$ and $\boldsymbol{F}_{2}$, which $\boldsymbol{F}_{\mathbf{1}}$ press the seal ring bracket and $\boldsymbol{F}_{\mathbf{2}}$ thrust the seal ring bracket. The two kinds of load are alternated disturibution to make the wavy pre-deformation on the end face of the seal ring.

\subsubsection{FEM analysis model}

ANSYS workbench is used to do the FEM analysis. The geometric model which is used for FEM analysis is created by Pro/Engineer. The fixture is circumferential symmetry, so there are two kinds of geometric models can be established. First is single-cycle model and another is whole cycle model. The single-cycle model is easier to calculate and is used to do the parametric research. The whole cycle model is used to study the synergy of press and thrust bolts. The two kinds of geometric models are shown in Figure 2

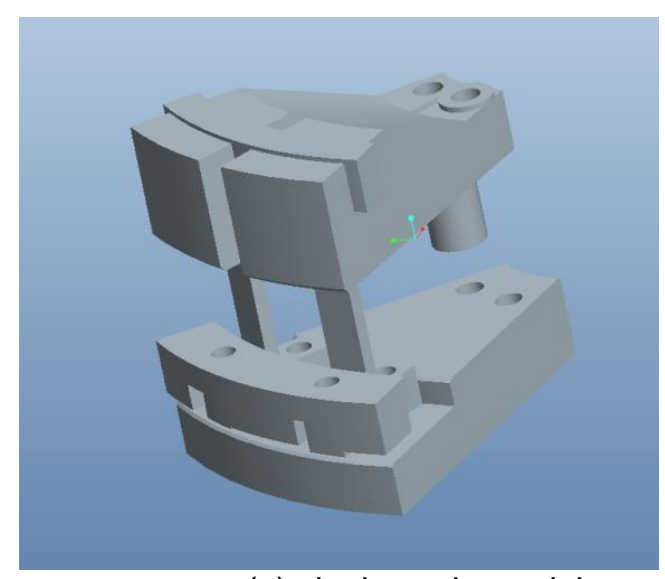

(a) single-cycle model

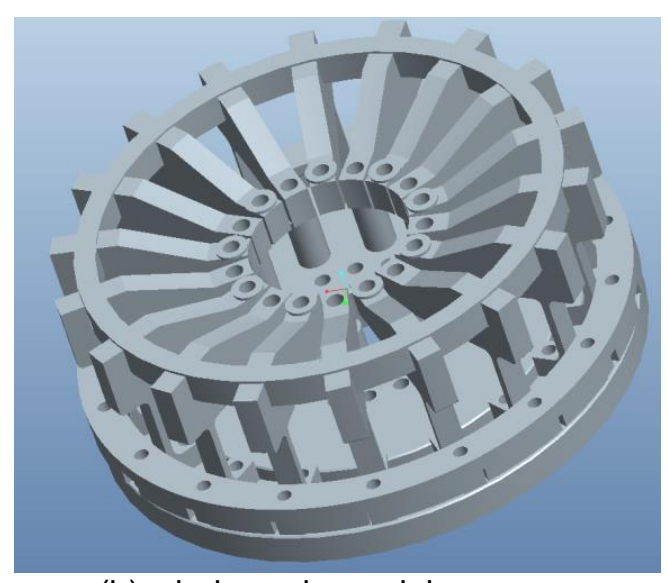

(b) whole cycle model

Figure 2. Geometric models for FEM

An equivalent pressure instead of the axial force of bolts is used as the applying load in ANSYS workbench.

\footnotetext{
* Technical contribution to the $2^{\text {nd }}$ International Brazilian Conference on Tribology - TriboBR 2014, November $3^{\text {rd }}$ to $5^{\text {th }}$, 2014, Foz do Iguaçu, PR, Brazil.
} 


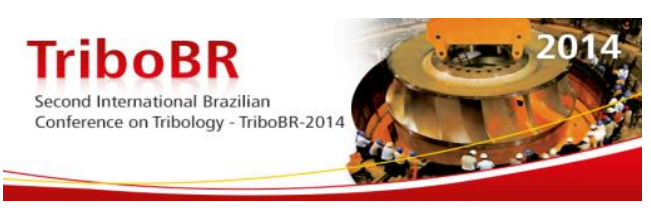

\subsubsection{Data processing method}

The node deformation is given by the ANSYS analysis. It's necessary to transfer this data to geometric parameters of wavy deformation, in order to compare the simulation results with the expected wavy deformation. The date process is introduced by MATLAB.

The wavy deformation geometric parameters include:

$\boldsymbol{h}_{\boldsymbol{a}}$-Waviness amplitude

$$
\mathrm{h}_{\mathrm{a}}=\frac{h_{\text {omax }}-h_{\text {omin }}}{2}
$$

Where

$\boldsymbol{h}_{\text {omax }}=$ The max value of deformation at WTD seal ring outside diameter;

$\boldsymbol{h}_{\text {omin }}=$ The min value of deformation at WTD seal ring outside diameter.

$\boldsymbol{w}_{\boldsymbol{d}}$-Dam width ratio: The dam width value divided seal ring value

$$
w_{d}=\frac{w}{D}
$$

Where

$\boldsymbol{w}=$ The width of dam;

$\boldsymbol{D}=$ The width of WTD seal ring.

$\boldsymbol{\alpha}-$ Ratio of waviness amplitude and slope

Where

$$
\alpha=\frac{h_{a}}{h_{t}}
$$

$\boldsymbol{h}_{\boldsymbol{t}}=$ The height of the outer diameter of the taper surface

And $\boldsymbol{h}_{\boldsymbol{t}}=\boldsymbol{h}_{\boldsymbol{a}}+\boldsymbol{h}_{\text {omin }}$

$\boldsymbol{\beta}$-Slope angle

$$
\alpha=\frac{h_{t}}{D}
$$

\subsection{Methods of Experimental Research}

\subsubsection{Experimental device}

Fixture that produce wavy face ring is shown in Figure 3.

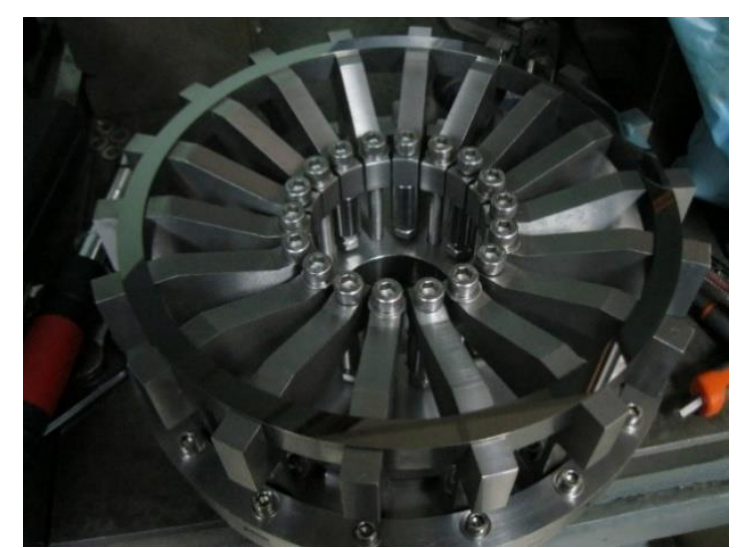

Figure 3. Fixture used to produce wavy face ring

\footnotetext{
* Technical contribution to the $2^{\text {nd }}$ International Brazilian Conference on Tribology - TriboBR 2014, November $3^{\text {rd }}$ to $5^{\text {th }}$, 2014, Foz do Iguaçu, PR, Brazil.
} 
Loading device: the Set torque wrench $(\mathbf{2} \sim \mathbf{1 2 . 5 N} \cdot \mathbf{m})$, the Spring dynamometer $(\mathbf{0} \sim \mathbf{3 0 N})$, Allen wrench and Load Lever. Loading device is used for measuring the magnitude of the torque applied.

Deformation observing and measuring equipment: Sodium lamp, Optical plane (diameter $150 \mathrm{~mm}$ and $300 \mathrm{~mm}$ ) and SLR cameras. The observation of wavy deformation is by light interference.

Processing equipment: Grinder (LAPMASTER SS-36H)

\subsubsection{Experimental procedure}

1) Mounting fixture and sea ring blanks.

2) Loading the predetermined torque on the bolts.

3) Using Sodium lamp and Optical plane to observe interference fringes.

4) Looping part 2 and part until proper interference fringes can be observed (9 continuous waves). Measuring the wavy amplitude by interference fringes; comparing with theoretical value.

5) Grinding wavy face ring.

6) After processing is completed, observing and measuring the wavy face ring.

\section{RESULTS AND DISCUSSION}

\subsection{The synergy of Pressure and Thrust Bolts}

The amplitude and continuity of the wavy deformation on the end face of seal ring is determined by the amount of the pressure and thrust force on the bolts.

The simulation results of pressure (13MPa) and thrust $(5,7,9,10 \mathrm{MPa})$ are shown in Figure 4.

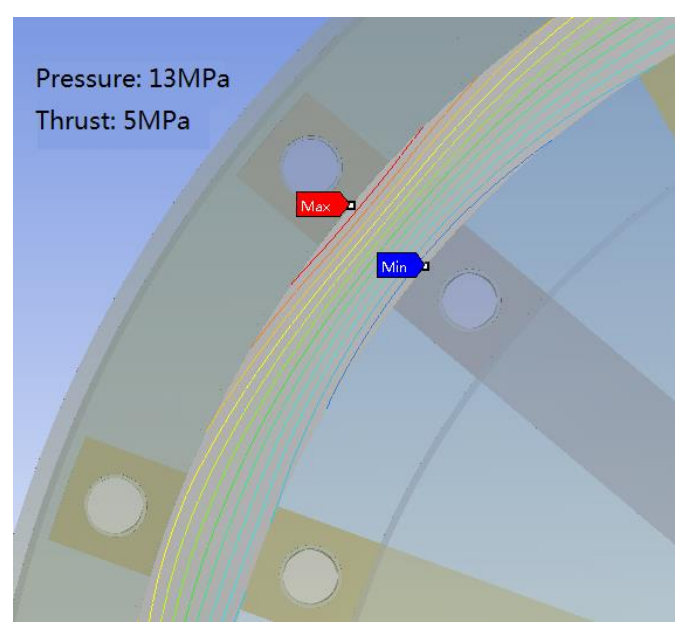

(a)

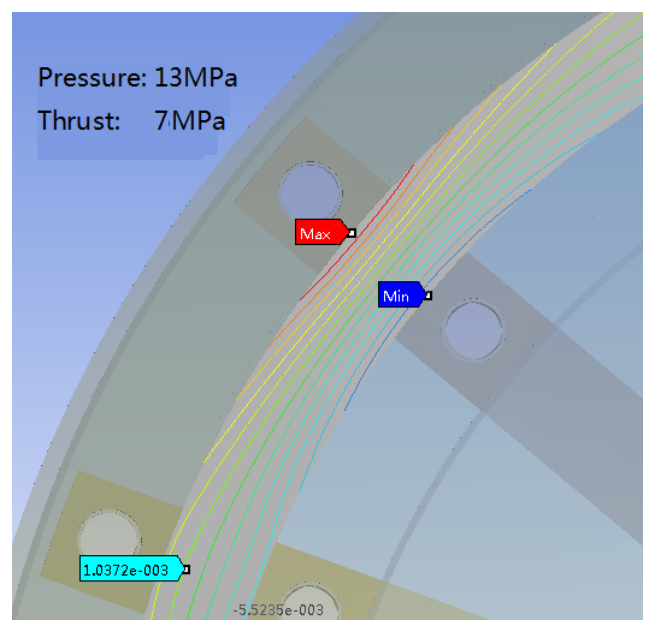

(b)

* Technical contribution to the $2^{\text {nd }}$ International Brazilian Conference on Tribology - TriboBR 2014, November $3^{\text {rd }}$ to $5^{\text {th }}$, 2014, Foz do Iguaçu, PR, Brazil. 


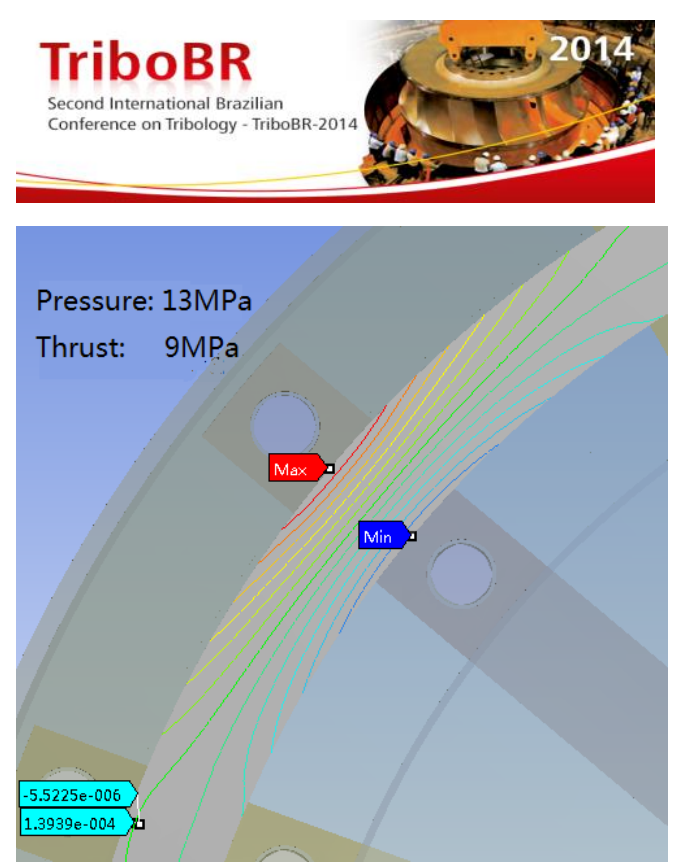

(c)

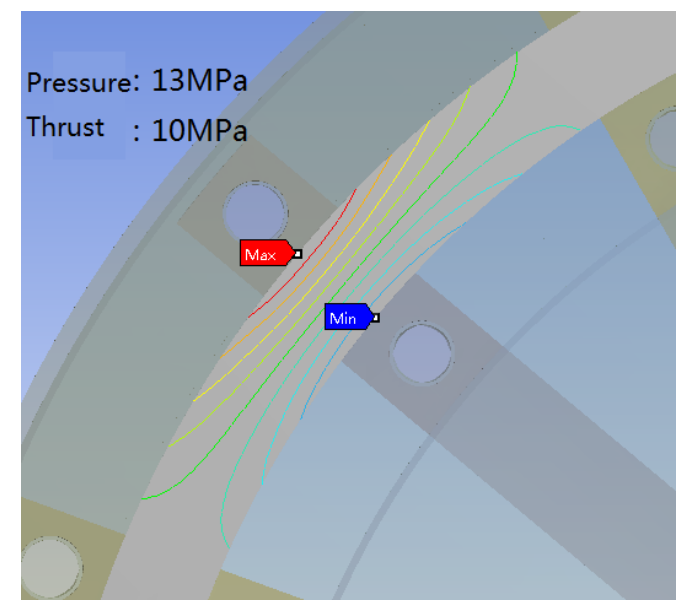

(d)

Figura 4. The simulation results of different thrust load with the same pressure loads.

When pressure load is fixed in $13 \mathrm{MPa}$, and the wavy deformation is gradually discontinuous with the thrust loads increases. It's necessary to choose proper magnitude of pressure and thrust torque to obtain a continuous wavy deformation.

\subsection{Effect of Processing Parameters on Wavy Deformation}

Firstly, the pressure value $(P)$ is assumed as constant and the thrust $(T)$ is varied. The relationship between $\boldsymbol{h}_{\boldsymbol{a}}$ and $T, P$

The relationship between wavy deformation amplitude and processing parameters is illustrated in Figure 5. Fixing the pressure value as the constant, the wavy amplitude $\boldsymbol{h}_{\boldsymbol{a}}$ increases proportionally with the increasing of the thrust value. When $\mathrm{T}=0, \boldsymbol{h}_{\boldsymbol{a}}$ increases when P increases. This result means T determines the lower limit of $\boldsymbol{h}_{\boldsymbol{a}}$.

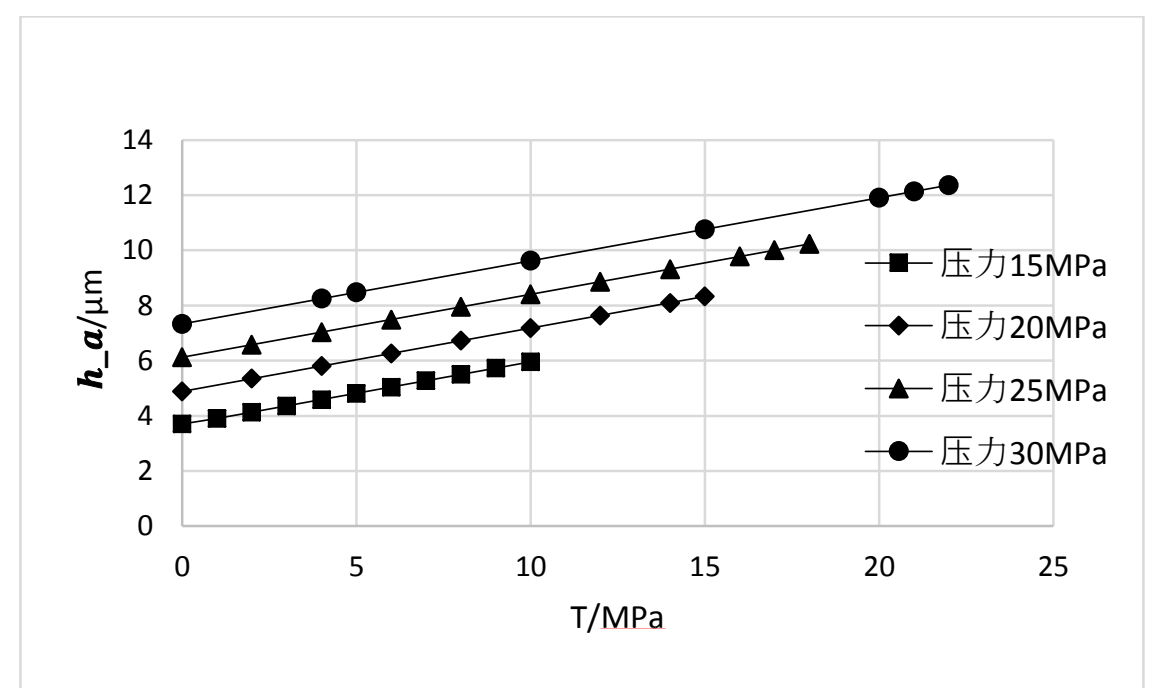

Figure 5. The Relationship between $\boldsymbol{h}_{\boldsymbol{a}}$ and $T, P$

The relationship between $w_{d}$ and $T, P$

The dam width of this pattern wavy deformation is not constant. According to the simulation results, the maximum and minimum value can be obtained shown in Figures 6 and 7.

* Technical contribution to the $2^{\text {nd }}$ International Brazilian Conference on Tribology - TriboBR 2014, November $3^{\text {rd }}$ to $5^{\text {th }}$, 2014, Foz do Iguaçu, PR, Brazil. 

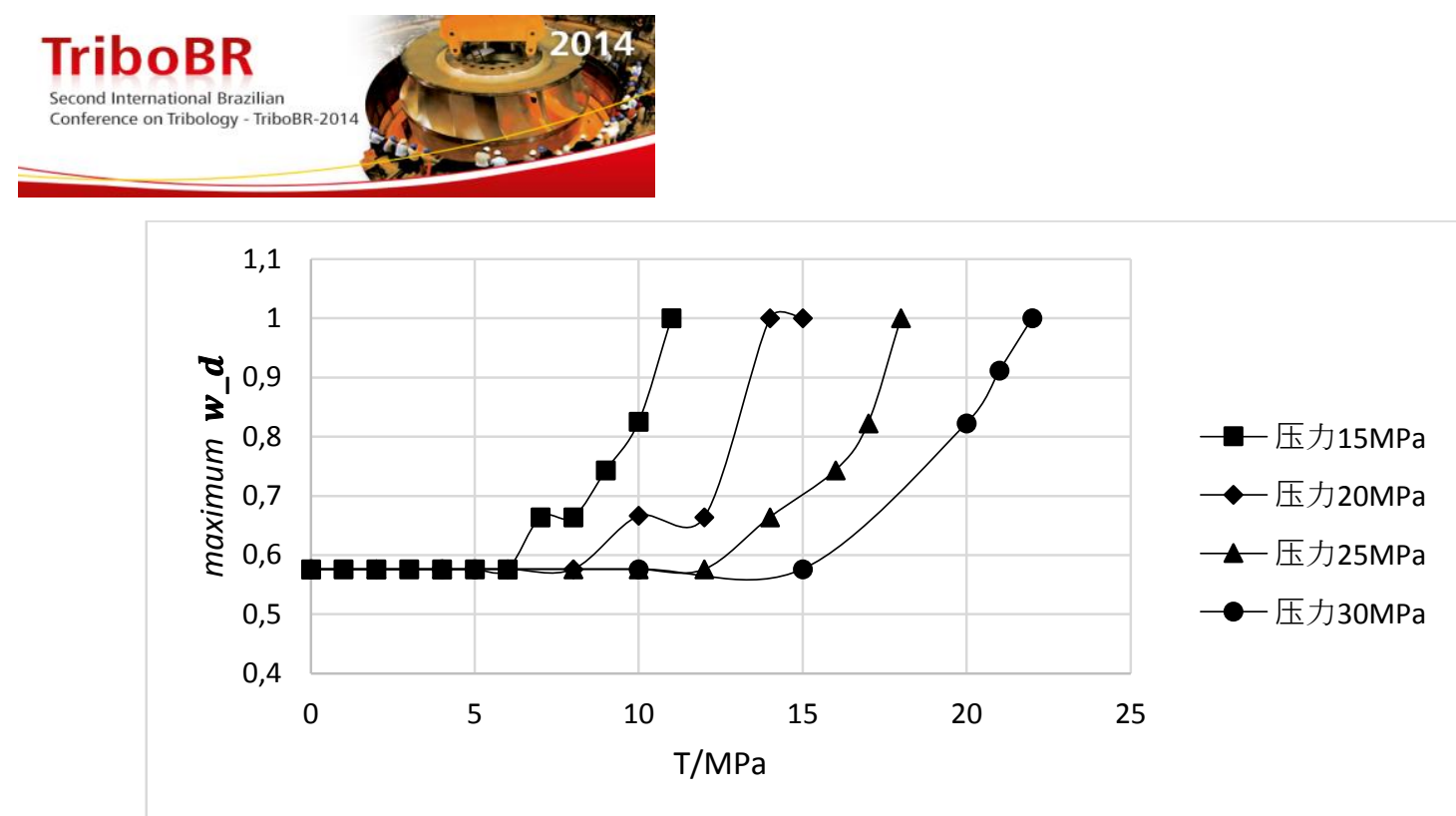

Figure 6. The relationship between maximum $\boldsymbol{w}_{\boldsymbol{d}}$ and $T, P$

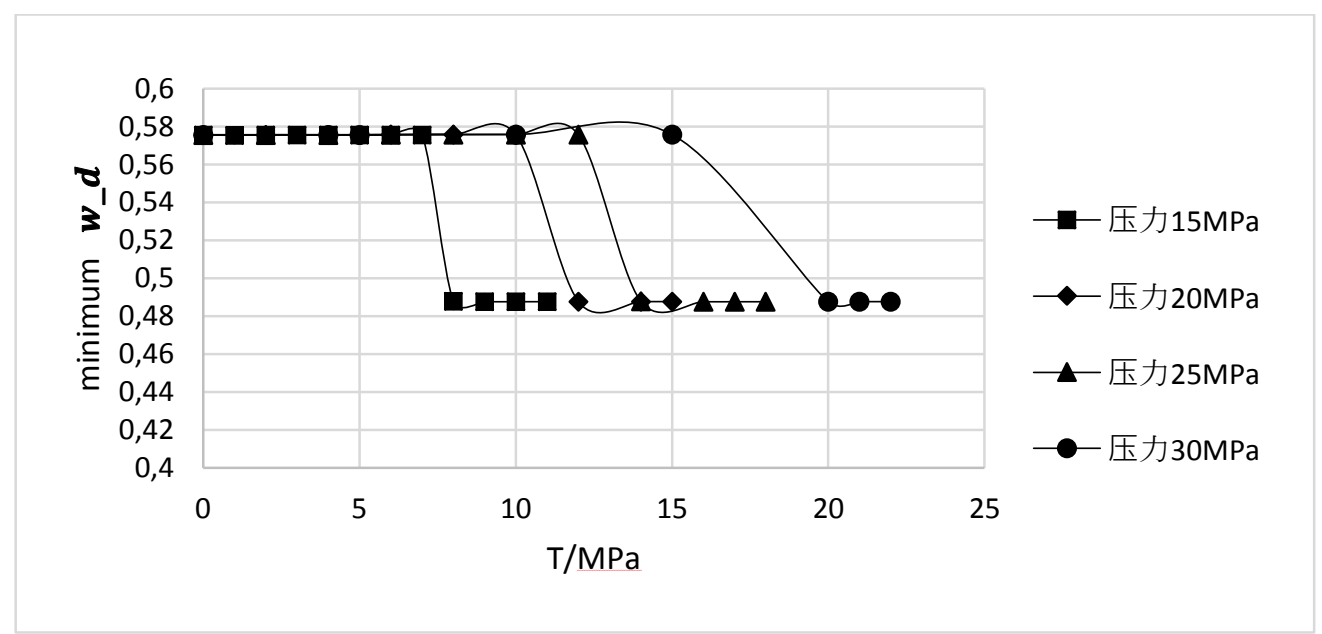

Figure 7. The relationship between minimum $\boldsymbol{w}_{\boldsymbol{d}}$ and $T, P$

As shown in Figure 6 , $\max \boldsymbol{w}_{\boldsymbol{d}}$ keep constant until the value of T gets to a transfer point. The value of the transfer point grows as $P$ increase. Beyond this point $\max w_{d}$ rises when $T$ goes up. The upper limit of $\max w_{d}$ is 1.

Figure 7 illustrates that $\min w_{d}$ has two plane regions as $T$ increases. Between this two regions, the trend of $\min w_{d}$ is down. The transfer point of min $w_{d}$ becomes larger when $T$ increases.

In fact, the constant part of max and min shouldn't exist. It may result from the size of grid and the program of data processing. Because of the deformation is tiny, the calculation results from the node deformation data may introduce calculating errors which made us cannot find the tiny deference of the $\max \boldsymbol{w}_{\boldsymbol{d}}$ or $\min \boldsymbol{w}_{\boldsymbol{d}}$.

The relationship between $\alpha$ and $T, P$

From Figure 8, it can be seen that $\alpha$ is the increase function of $T$. And the bigger $P$ is, the more increasing rate $\alpha$ is. When $T=0$, whatever $P$ is, $\alpha=0.2$.

* Technical contribution to the $2^{\text {nd }}$ International Brazilian Conference on Tribology - TriboBR 2014, November $3^{\text {rd }}$ to $5^{\text {th }}, 2014$, Foz do Iguaçu, PR, Brazil. 

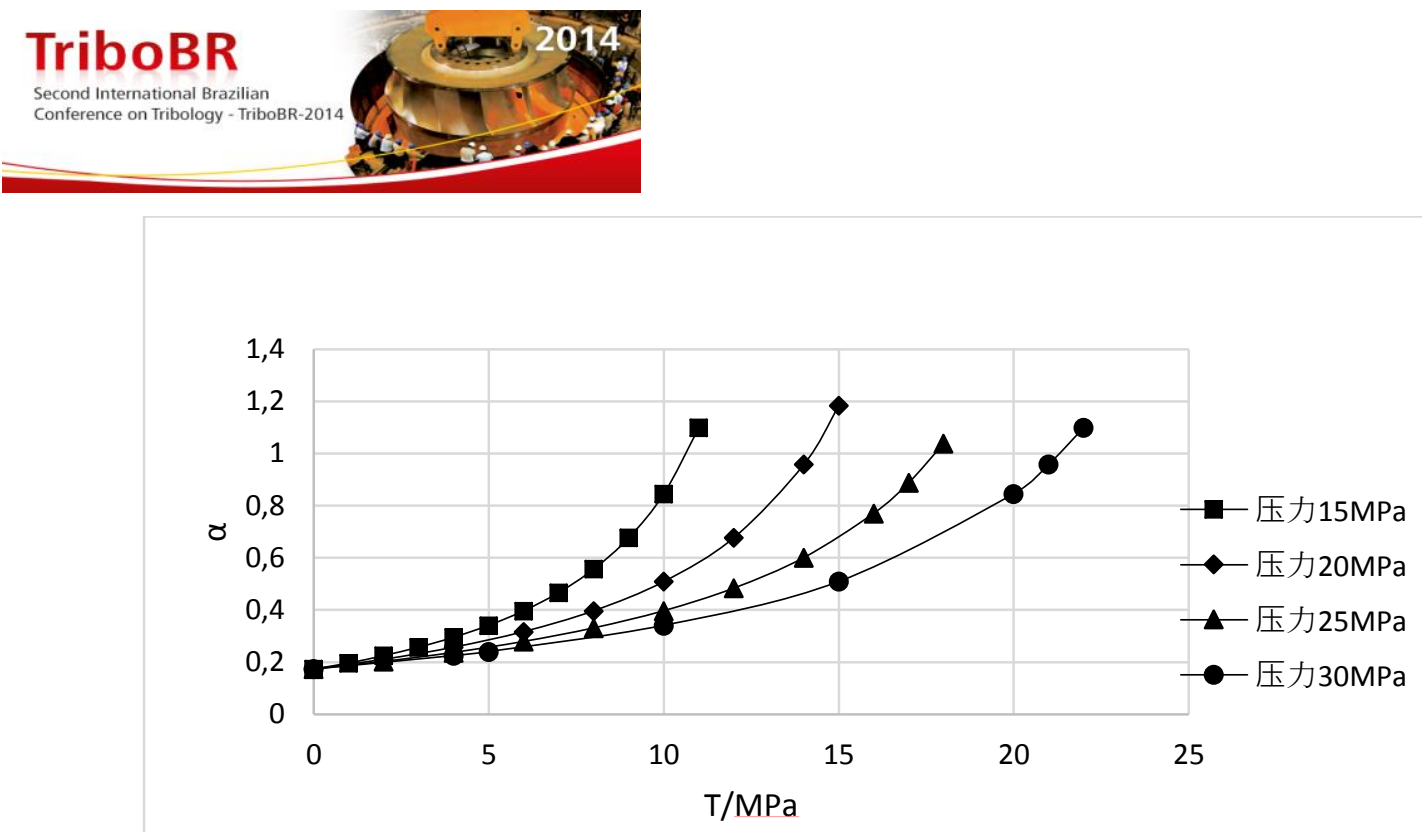

Figure 8. The relationship between $\alpha$ and T, P

The relationship between $\beta$ and $T, P$

As shown in Figure 9, $\boldsymbol{\beta}$ decreases when $T$ increases. And the decreasing rate decreases as $P$ increases. When $T=0, \boldsymbol{\beta}$ increases as $P$ increases. The value of $P$ determines upper limit of $\boldsymbol{\beta}$.

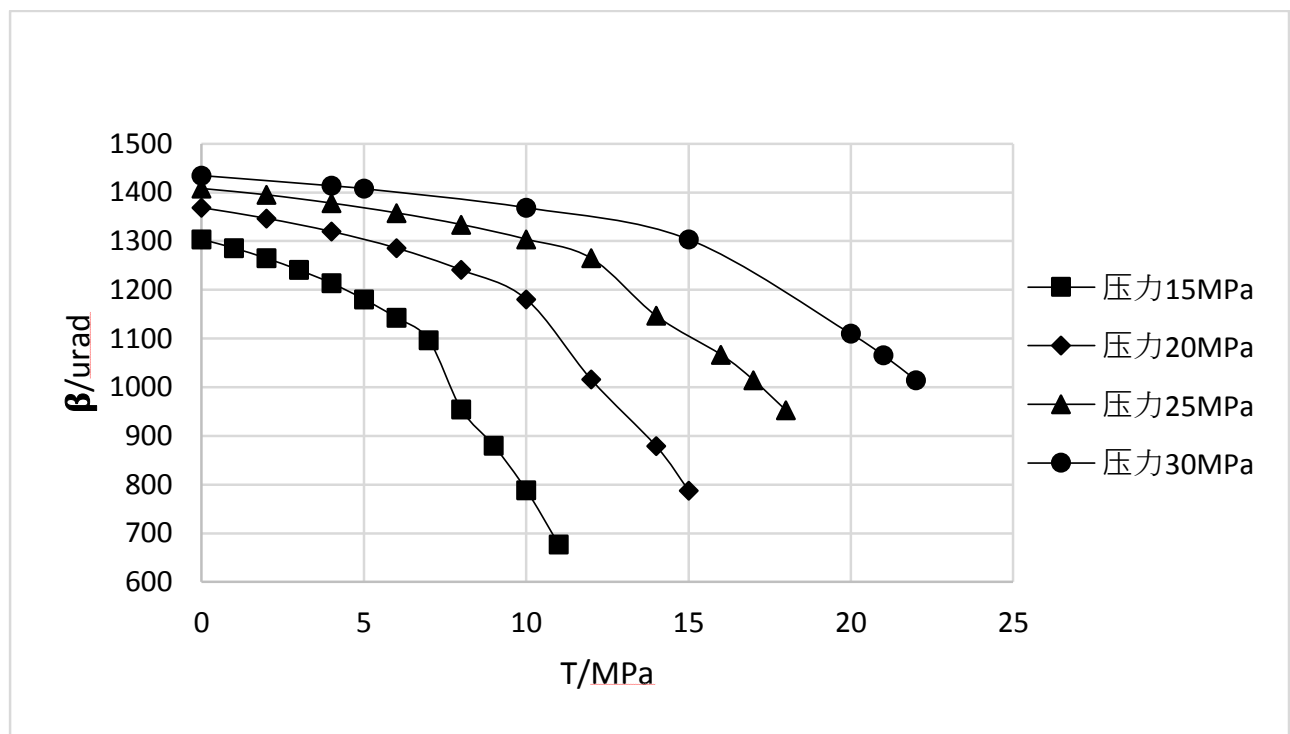

Figure 9. The relationship between $\beta$ and T, $P$

Secondly, the thrust value $(T)$ is assumed as constant and the pressure $(P)$ is varied. In order to obtain the geometric parameters of WTD seal given by Liu [8] et al, the processing parameters can be selected to manufacture the wavy face ring. In this paper, the operation parameters are $\mathrm{P}=30 \mathrm{MPa}, \mathrm{T}=20 \mathrm{MPa}$. In order to operate easily, these parameters are transferred to torque of bolts.

\subsection{Experimental Research}

\subsubsection{Feasibility for observing the formation of waviness}

Using $150 \mathrm{~mm}$ optical plane to observe the interference fringes, adjust to the sodium light, and photograph some pictures, shown in Figure 3.7.

* Technical contribution to the $2^{\text {nd }}$ International Brazilian Conference on Tribology - TriboBR 2014, November $3^{\text {rd }}$ to $5^{\text {th }}$, 2014, Foz do Iguaçu, PR, Brazil. 

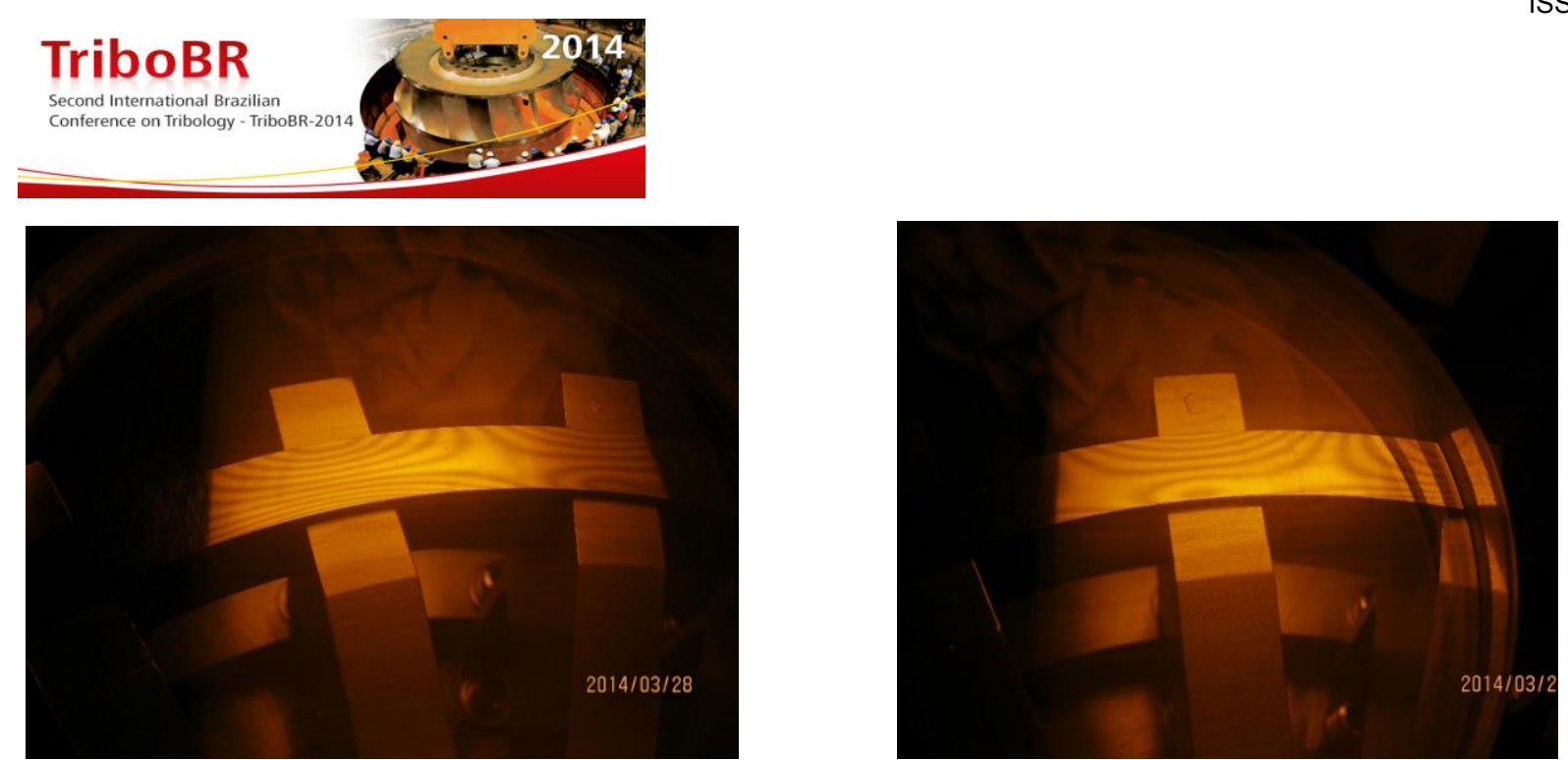

Figure 10. Interference fringes of wavy deformation using $150 \mathrm{~mm}$ optical plane

As shown in Figure 10, there are clearly interference fringes which show the wavy deformation.

\subsubsection{Waviness amplitude measurement}

After careful adjustment, high resolution pictures are photographed. Two of them are shown in Figure 11.

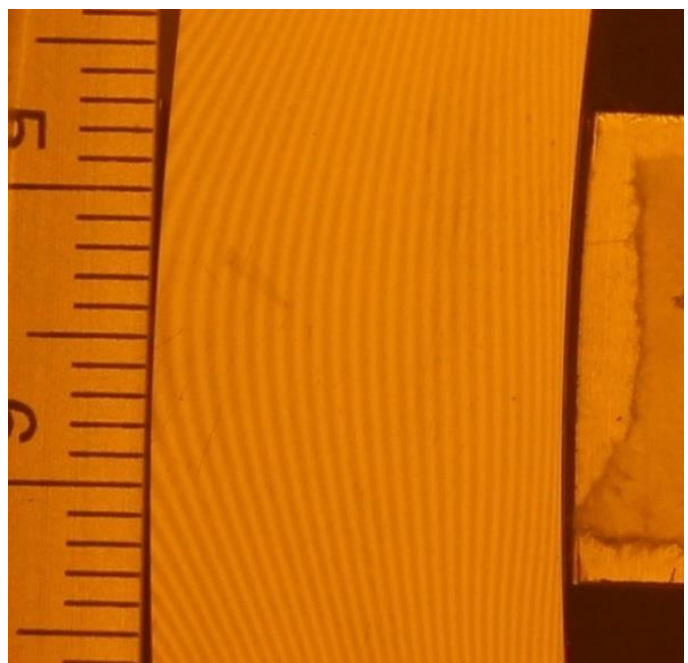

(a) Interference pattern on peak position

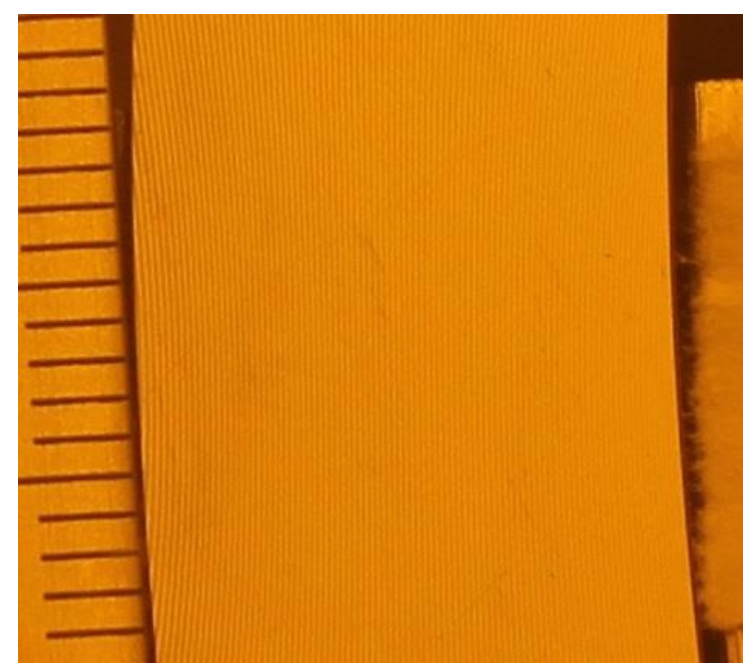

(b) interference pattern on trough position

Figure 11. Interference fringes of wavy deformation using $300 \mathrm{~mm}$ optical plane

The width of waviness area on peak position and trough position is confirmed. Taking the ruler placed near the ring surface as length reference to measure the waviness area, then figure out how many fringes in this area. Finally, it's easy to calculate the amplitude of wavy deformation.

The waviness area is marked with red line in the pictures as shown in Figure 12.

* Technical contribution to the $2^{\text {nd }}$ International Brazilian Conference on Tribology - TriboBR 2014, November $3^{\text {rd }}$ to $5^{\text {th }}$, 2014, Foz do Iguaçu, PR, Brazil. 

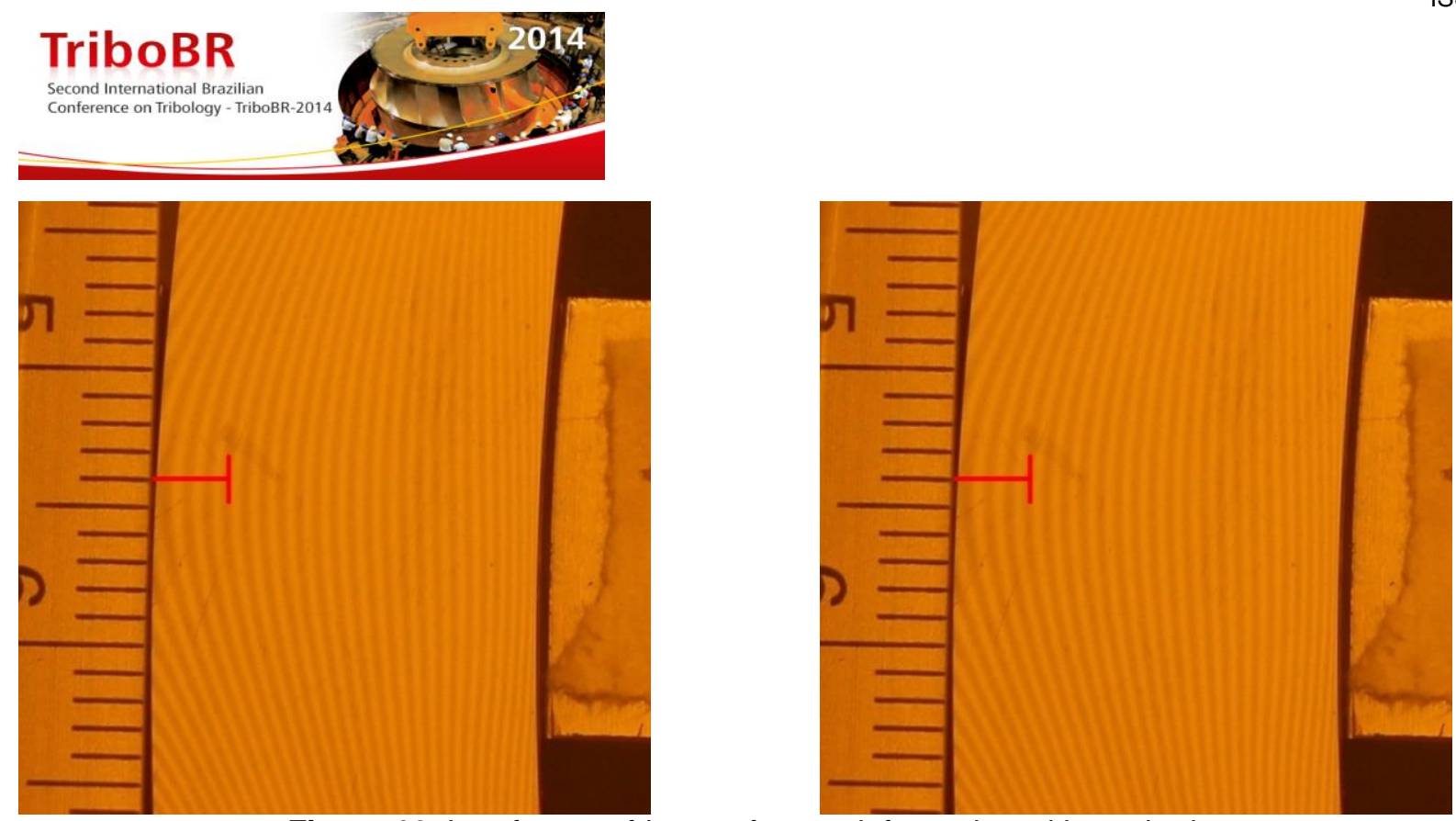

Figure 12. Interference fringes of wavy deformation with marked

The same method is used to deal with all interference fringes pictures. The peak of wavy deformation is shown in table 1.

Table 1. Peak of wavy deformation

\begin{tabular}{cccc}
\hline $\begin{array}{c}\text { Num of } \\
\text { Bolt }\end{array}$ & $\begin{array}{c}\text { Num of } \\
\text { Fringes }\end{array}$ & Fringes difference of adjacent positions & $\begin{array}{c}\text { Peak of wavy } \\
\text { deformation }(\mu \mathrm{m})\end{array}$ \\
\hline T1 & 4 & 59 & 17.7 \\
P1 & 63 & 59 & 17.7 \\
T2 & 4 & 57 & 17.1 \\
P2 & 61 & 57 & 17.1 \\
T3 & 4 & 50 & 15 \\
P3 & 54 & 50 & 15 \\
T4 & 4 & 50 & 15 \\
P4 & 54 & 50 & 15 \\
T5 & 4 & 60 & 18 \\
P5 & 64 & 60 & 18 \\
T6 & 4 & 60 & 18 \\
P6 & 64 & 60 & 18 \\
T7 & 4 & 46 & 13.8 \\
P7 & 50 & 47 & 14.1 \\
T8 & 3 & 47 & 14.1 \\
P8 & 50 & 46 & 13.8 \\
T9 & 4 & 58 & 17.4 \\
P9 & 62 & 58 & 17.4 \\
\hline
\end{tabular}

In the chart, ' $T$ ' represents 'thrust bolt', ' $P$ ' represents 'pressure bolt'. The design amplitude of waviness is about $\mathbf{1 0 \mu \mathrm { m }}$ and the peak is about $\mathbf{2 0 \mu \mathrm { m }}$.

\subsubsection{The result of wavy face ring after grinding}

Follow the step of part 3.3.2, the wavy face ring pro-loaded is manufactured by grinder for 2 minutes. The surface of the ring is shown in Figure 13.

*Technical contribution to the $2^{\text {nd }}$ International Brazilian Conference on Tribology - TriboBR 2014, November $3^{\text {rd }}$ to $5^{\text {th }}$, 2014, Foz do Iguaçu, PR, Brazil. 


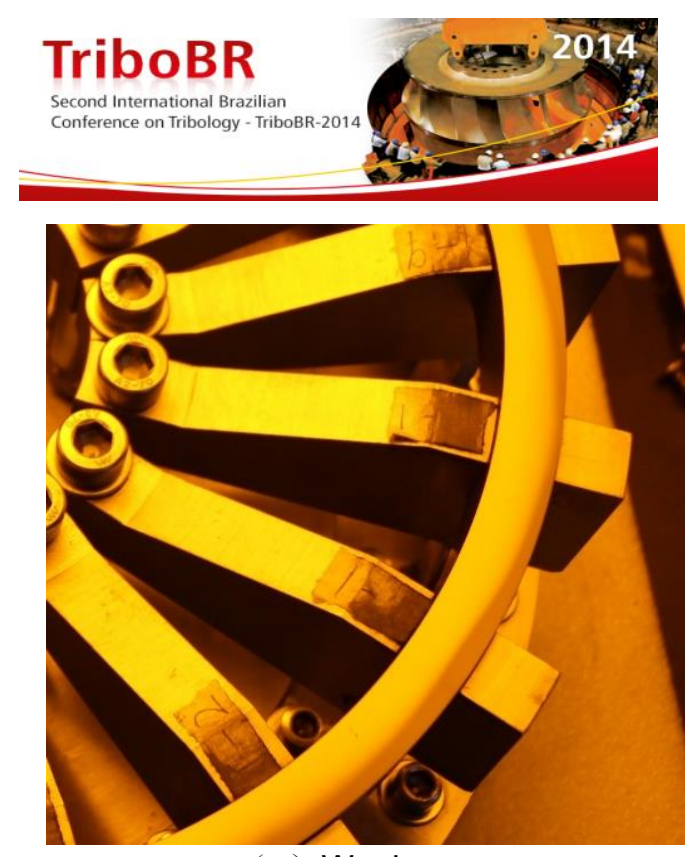

(a) Waviness wear scar

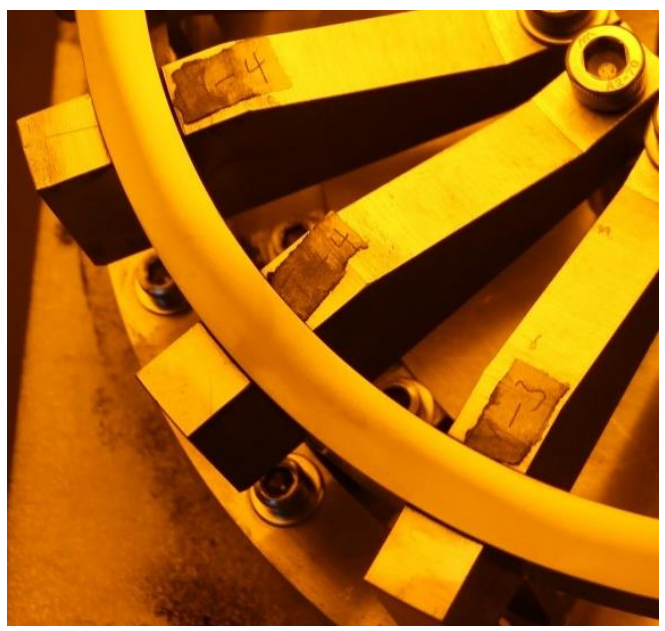

(b) Non-waviness wear scar

Figure 13. Wear scar after grinding

As shown in Figure 13, some part of the ring surface have waviness wear scar and the other part don't have. This is because the waviness which is distant with each other, don't have enough symmetry and continuity.

\subsubsection{Error analysis}

From the experiments, the wavy deformations during the pre-load process and the grinding are both different with theoretical value. It's very important to analyze the reason of the errors. Some measures should be put forward to improve the method of forming WTD seal ring.

The most important reason is the value of load is not completely same as theoretical value.

Firstly, the loading process is manual operation. Every bolt is independent load. So it's a hard to keep the load on each bolt equally. It's obvious that with the wrong loads, right wavy deformation can't get. To improve this question, carefully operation is necessary. And it's important to choose a proper way that adds load on each bolt. For example, the bolts should be screwed one after one circumferentially or diagonal. And good lubrication of screws is also very important to control the load accuracy.

Secondly, the position of optical plane is still a very important aspect that introduces the errors. When the optical plane size is smaller than wavy face ring blank, the relative position of optical plane and wavy face ring blank can't be right in which the interference fringes distorts. Because of this, the measurement of amplitude must be errors. The right or false position of optical plane is shown in shown in Figure 14.

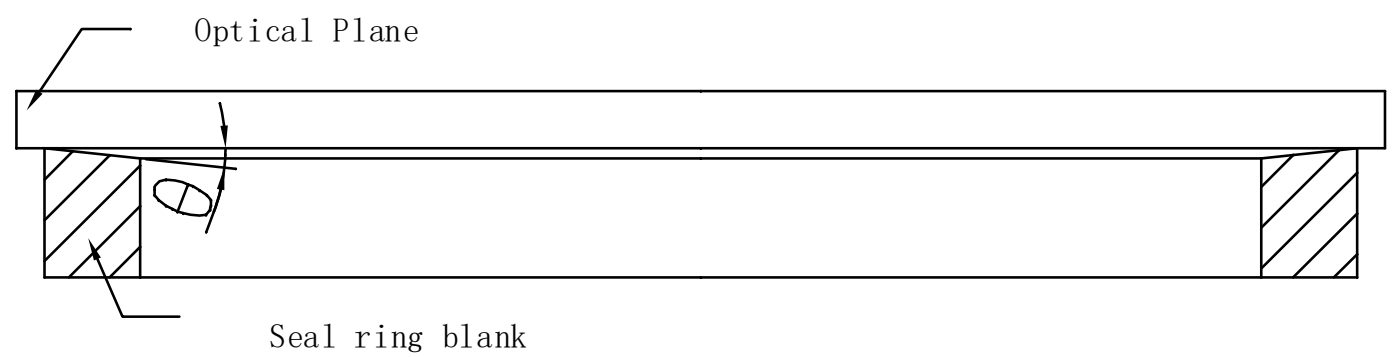

(a) Normal position of optical plane and seal ring blank

* Technical contribution to the $2^{\text {nd }}$ International Brazilian Conference on Tribology - TriboBR 2014, November $3^{\text {rd }}$ to $5^{\text {th }}$, 2014, Foz do Iguaçu, PR, Brazil. 

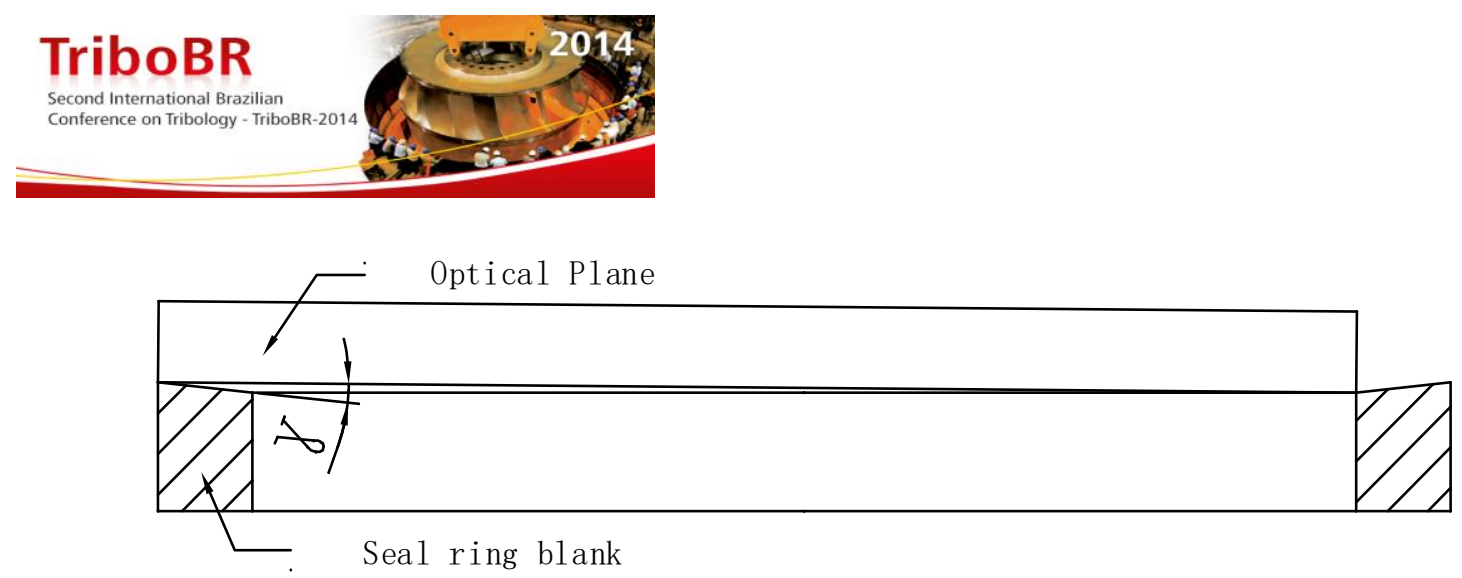

(b) Wrong position of optical plane and seal ring blank

Figure 14. The right or false position of optical plane

If the optical plane is in wrong position, it's very hard to adjust the load to get a circumferential symmetry and same amplitude wavy deformation because the whole interference fringes cannot be gotten. Then, the wear scar error occurs.

According to the previous analysis, the main method to reduce errors is to improve the loading way and to choose a proper optical plane.

\section{CONCLUSIONS}

In this paper, both theoretical and experimental researches have been done about a pre-deformation method that forms the wave face ring. It can be concluded as followed: 1) The quantitative relationship between processing parameters and wave face geometry parameters are obtained by using the FEM (Finite Element Method) ; 2) The proper processing parameters for forming the full size WTD seal ring which is used for testing is chosen according to the theoretical analysis, and the feasibility of this method is confirmed by the experiment; 3) Some feasible solutions, which are very useful for further experimental study on the manufacture of wavy face ring, are developed for the difficulties encountered in the experiment.

\section{Acknowledgments}

This work was supported by the National Basic Research Program of China (973) (Grant No. 2009CB724304)

\section{REFERENCES}

1 Iny, E. H. A Theory of Sealing with Radial Face Seals, Wear, 1971; 18(1): 51-69.

2 Lebeck, A. O. Principles and Design of Mechanical Face Seals. New York: Wiley; 1991.

3 Young, L. A. The Design and Testing of a Wavy-tilt-dam Mechanical Face Seal, Lubrication Engineering, 1989; 45(5): 322-329.

4 Young, L. A., Key, B., Philipps, R. and Svendsen, S. Mechanical Seals with Laser Machined Wavy SiC Faces for High Duty Boiler Circulation and Feedwater Applications, Lubrication Engineering, 2003; 59(4): 30-39.

5 Xu, H. P., Yan, W. P. and Zhu, Q. Study of Wavy-tilt-dam Mechanical Seal, Journal of Shanghai University(Natural Science), 1996; 2(3): 308-315.

6 Liu W, Liu Y, Wang YM, Peng XD. Parametric Study on a Wavy-Tilt-Dam Mechanical Face Seal in Reactor Coolant Pumps. Tribol T. 2011;54(6):878-86.

7 Liu W, Liu Y, Zhai JJ, Huang WF, Wang YM. Three-Dimensional Flow-Heat Coupling Model of a Wavy-Tilt-Dam Mechanical Seal. Tribol T. 2013;56(6):1146-55.

8 Liu W, Liu Y, Huang WF, Suo SF, Wang YM. Effect of disturbances on the dynamic performance of a wavy-tilt-dam mechanical seal. Tribol Int. 2013;64:63-8.

* Technical contribution to the $2^{\text {nd }}$ International Brazilian Conference on Tribology - TriboBR 2014, November $3^{\text {rd }}$ to $5^{\text {th }}$, 2014, Foz do Iguaçu, PR, Brazil. 


\section{TriboBR}

Second International Brazilian

Conference on Tribology - TriboBR-2014

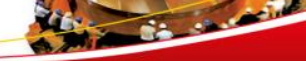

9 YOUNG LA. Wavy face mechanical seal ring manufacturing method - utilises temperature-induced size differential between a thermally expandable shrink band and seal ring blank to create wave pattern, together with ring face surface treatment using lapping machine..(US5833518-A).

10 Hengzhen P, Ping Z, Zhuji J. A sealing ring processing of pre-deformation force loading and loading fixture: China, CN 103029037 A.

* Technical contribution to the $2^{\text {nd }}$ International Brazilian Conference on Tribology - TriboBR 2014, November $3^{\text {rd }}$ to $5^{\text {th }}$, 2014, Foz do Iguaçu, PR, Brazil. 